\title{
Surgical management of ankyloglossia and abnormal thick frenum-a case report
}

\author{
Dr.Munaza Shafi ${ }^{1}$, Dr.Prabhati Gupta ${ }^{2}$, Dr.Reyaz Ahmed ${ }^{3}$, Dr.Nawal Khan ${ }^{4}$, \\ Dr.Zahoor Ahmad Teli ${ }^{5}$, Dr.Jawahir Ahmad Ganai ${ }^{6}$ \\ I,2,3 (P.G department of periodontics, Govt.Dental College,Srinagar, India) \\ 4,5,6 (Junior Resident, Govt.Dental College,Srinagar,India)
}

\begin{abstract}
Ankyloglossia, or tongue-tie, is a congenital condition that results when the inferior lingual frenulum is too short and is attached to the tip of the tongue, limiting its normal movements. Ankyloglossia has been reported to cause feeding difficulties, dysarthria, dyspnea, and social or mechanical problems. Ankyloglossia occurs in $1.7 \%$ of all neonates. The pathogenesis of ankyloglossia is not known. This article reports the surgical management of a patient having ankyloglossia and abnormally thick frenum associated with restricted movement of tongue and midline diastema respectively. The treatment involved surgical removal of the lingual and labial frenum, which healed uneventfully.
\end{abstract}

Key words: ankyloglossia, lingual frenum, midline diastema

\section{Introduction}

Ankyloglossia, commonly known as tongue tie, is a congenital oral anomaly which may decrease mobility of the tongue tip ${ }^{(1)}$ and is caused by an unusually short, thick lingual frenulum, a membrane connecting the underside of the tongue to the floor of the mouth. Tongue tie is a condition in which the midline sheath of tissue attached to the base of the tongue (lingual frenulum) is attached too forward on the tongue, causing restriction of tongue motion. ${ }^{(2,3)}$ Ankyloglossia occurs in $1.7 \%$ of all neonates. Partial ankyloglossia (also called tongue-tie ) is caused by a frenum of the tongue that is abnormally short or is attached too close to the tip of the tongue.This condition may be surgically corrected by simple excision.

Ankyloglossia can affect feeding, speech, and oral hygiene as well as have mechanical/social effects. ${ }^{(4)}$ Ankyloglossia can also prevent the tongue from contacting the anterior palate. This can then promote an infantile swallow and hamper the progression to an adult-like swallow which can result in an open bite deformity.

The management of ankyloglossia varies among different health care providers. Pediatricians, pediatric surgeons, otolaryngologists , dentists, lactation specialists, and speech language pathologists ${ }^{(5)}$ are all involved in the care of tongue-tie, but there is little consensus regarding the significance in symptomatology, its causal relationship to dysfunction, and its management.

\section{Case report}

This paper reports surgical management of ankyloglossia as well as abnormally thick labial frenum in a 12 year old patient who had severe restriction of his tongue movements and midline diastema. A 12 year old patient reported with chief complaint of difficulty in complete protrusion of the tongue. His ENT and physical examination was normal.There was recession in relation to mandibular incisors lingualy. When the patient was asked to retrude the tongue, slight blanching was seen lingual to the anterior teeth with midline diastema in lower anteriors. The patient showed speech difficulties associated with lingual movement limitation. Frenectomy was recommended as treatment, on lingual as well as labial side.After anesthesia, hemostatic pliers were used for apprehend the frenulum, and an scalpel was used for its releasing. Surgical wound was sutured with silk suture . Following, post-operative instructions comprising measurements for avoiding hemorrhages and the use of non-narcotic painkillers for controlling pain discomfort, were performed. The sutures were removed one week following the procedure. The post-operative period was uneventful. The following exercises were advised: i) Stretch the tongue up towards the nose, then down towards the chin and repeat, ii) Open the mouth widely and touch the big front teeth with the tongue with mouth still open, iii) Shut the mouth and poke it into left and right cheek to make a lump: for 3 to 5 minute bursts, once or twice daily for 3 or 4 weeks postoperatively. The routine follow up at 4 weeks showed an extremely happy patient with improved tongue protrusion and normal speech. 


\section{Discussion}

Ankyloglossia is a rare congenital oral anomaly that causes difficulty in breast feeding and speech articulation. In many individuals ankyloglossia is asymptomatic and may resolve spontaneously ${ }^{(6)}$ The ankyloglossia can be classified into four classes based on KOTLOW'S assessment;

Clinically acceptable - normal range of free tongue greater than $16 \mathrm{~mm}$,

Class I Mild ankyloglossia: 12 to $16 \mathrm{~mm}$

Class II Moderate ankyloglossia: 8 to $11 \mathrm{~mm}$

Class III Severe ankyloglossia: 3 to $7 \mathrm{~mm}$

Class IV Complete ankyloglossia: less than $3 \mathrm{~mm}$

The pathogenesis of ankyloglossia is not known. Ankyloglossia can be a part of certain rare syndromes such as X-linked cleft palate (OMIM 303400) ${ }^{(7)}$ and van der Woude syndrome (OMIM 119300) ${ }^{(8)}$ Most often ankyloglossia is seen as an isolated finding in an otherwise normal child. In the case reported here, ankyloglossia presented a social and clinical relevance, since it caused morphofunctional modifications. The child showed difficulty in speech in association with limitation of tongue's movements, besides an abnormal pattern of deglutition due to a short lingual frenulum that limited the amplitude of tongue's movements. The child also displayed difficulty in articulating labial-dental words. In daily clinical practice, tongue-ties are of importance for the periodontist because they are a frequent finding in patients. ${ }^{(9)}$ A significant association between frenal involvement and gingival recession has been reported in the literature ${ }^{(10)}$

\section{Conclusion}

To conclude, if severe/complete ankyloglossia is present in adult there is usually an obvious limitation of the tongue protusion, elevation and speech problems, which can be improved by surgical intervention.

\section{References}

[1] Messner AH, Lalakea ML. "The effect of ankyloglossia on speech in children".Otolaryngology--head and neck surgery : official journal of American Academy of Otolaryngology-Head and Neck Surgery 2002;127:539-545.

[2] M.Obladen Much Ado about Nothing: Two Millenia ofControversy on Tongue-Tie. Neonatology. 2009 Aug 25;97(2):83-

[3] M.W. Chu, D.C. Bloom. Posterior ankyloglossia: a case report. Int J Pediatr Otorhinolaryngology 2009,73:881-3

[4] Lalakea, M. Lauren, Messner, Anna H. Ankyloglossia: The adolescent and adult perspective. Otolaryngology - Head and Neck Surgery. 2003;128:746-752.

[5] A. Kummer, Ankyloglossia: To clip or not to clip? That's the question, The ASHA Leader 10 (December (17)) (2005) 6-7, 30

[6] Oringer MJ Electrosurgery for definitive conservative modern periodontal surgery Dent clin North Am vol13; 53: 1969

[7] Moore GE, Ivens A, Chambers J, Farrall M, Williamson R, Page DC, et al. Linkage of an X-chromosome cleft palate gene. Nature. 1987;326:91-92.

[8] Burdick AB, Ma LA, Dai ZH, Gao NN. Van Der Woude syndrome in two families in China. J Craniofac Genet Dev Biol 1987;7:413-418.

[9] Suter VGA and Bornstein MM. Ankyloglossia: Facts and Myths in Diagnosis and Treatment. J Periodontol 2009;80:1204-1219.

[10] Trott JR, Love B. An analysis of localized gingival recession in 766 Winnipeg High School students. Dent Pract Dent Rec 1966;16:209-213.

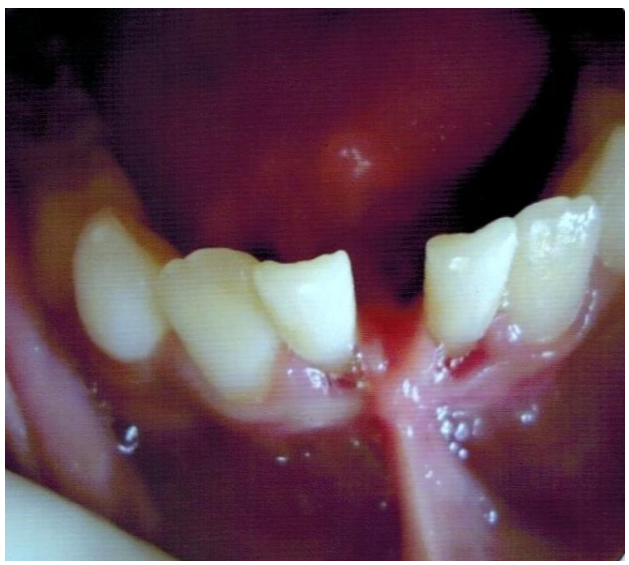

Preoperative view 


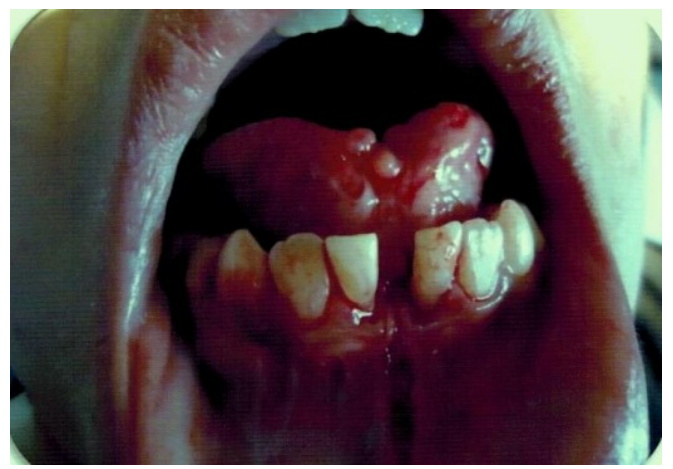

Labial as well as lingual frenum removed

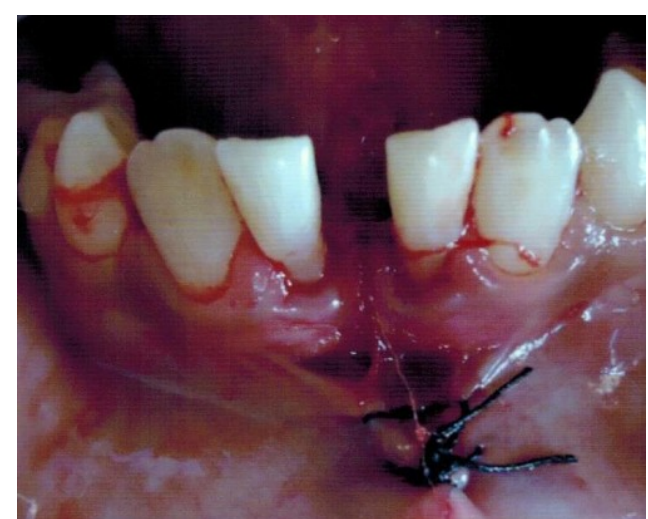

Sutures placed

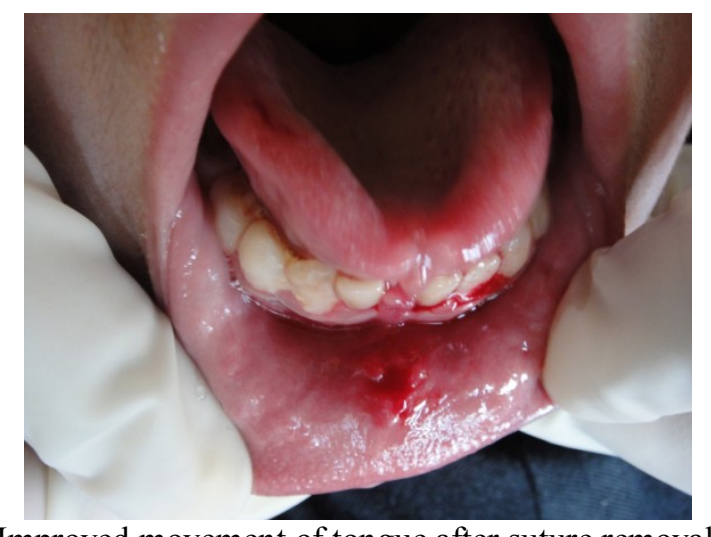

Improved movement of tongue after suture removal 